\title{
Docetaxel Weekly with Metastatic Breast Cancer
}

\author{
Chris Twelves \\ Cancer Research UK Clinical Centre in Leeds, Cancer Research Building, St James's University Hospital, Leeds, UK
}

The taxanes, docetaxel and paclitaxel, are an integral part of treatment for women with breast cancer in the metastatic, and increasingly now the adjuvant, setting. They have high levels of activity in breast cancer, but with significant toxicities. Whilst the enthusiasm for novel, targeted agents is appropriate and understandable, there remains a need to optimise our use of established cytotoxins such as docetaxel that form the back-bone of standard treatments. Warm et al. [1] describe their experience with docetaxel given weekly rather than the more usual 3-weekly schedule.

Traditionally, cytotoxins are administered every 3 weeks. In most cases this is not because 3-weekly administration is superior to other schedules in terms of efficacy or tolerability. Rather, 3-weekly treatment reflects the usual pattern of antiproliferative toxicities, in particular myelosuppression, whereby blood counts have recovered by day 22 allowing treatment to proceed. Both paclitaxel and docetaxel were administered every 3 weeks in initial studies, and using this schedule the US Food and Drug Administration approved paclitaxel 175 $\mathrm{mg} / \mathrm{m}^{2}$ and docetaxel $60-100 \mathrm{mg} / \mathrm{m}^{2}$ in metastatic breast cancer (MBC). More recently, weekly administration has been explored as a means of improving the therapeutic index of the taxanes, in particular reducing myelosuppression, as reviewed by Eniu et al. [2].

Warm et al. [1] present a retrospective analysis of 25 women with $\mathrm{MBC}$ receiving weekly docetaxel $25-40 \mathrm{mg} / \mathrm{m}^{2}$. The overall response rate was $36 \%$, and toxicity appeared acceptable. So, how should we interpret this paper? First, we should remember that this was not a tightly controlled, prospective study, and only a relatively small group of patients are reported. As such it cannot provide proof of efficacy as would a conventional phase II or III study. The authors should, therefore, be cautious in stating in the introduction that the goal was to 'test the hypothesis of improved toxicity profile and efficacy ...' with weekly treatment; the design and number of patients did not allow formal hypothesis testing. Likewise, the authors used WHO criteria to assess response, not the RECIST criteria that would be used in clinical trials today, making crossstudy comparisons difficult. Statistical analyses are shown, but it is not clear whether these analyses were prospectively planned; they would anyhow have limited power to detect or exclude differences in a small group of patients.

Reports such as this should not aspire to being phase II studies. Their value lies in describing experience with a clinically relevant regimen in a 'real life' situation that often better reflects standard clinical practice than does a clinical trial. For example, many patients seen in every day practice do not match the eligibility criteria of pivotal studies. As clinicians we need, therefore, to adapt trial findings for our patients. In this context, the authors used interesting criteria to determine starting dose. The fittest patients, with Karnofsky Performance Status (KPS) $\geq 90 \%$, received docetaxel $35-40 \mathrm{mg} / \mathrm{m}^{2}$, which is close to the maximum tolerated dose in phase I studies; those with KPS $\geq 70 \%$ but $<90 \%$ received $25-30 \mathrm{mg} / \mathrm{m}^{2}$. Treatment was well tolerated, with only mild myelosuppression, but there appeared to be more toxicity in the patients receiving the higher doses of docetaxel. This perhaps calls into question whether tailoring dose to KPS does level out toxicity between fitter and less fit patients, but the approach is worthy of further evaluation.

Efficacy was clearly seen with responses in 9 of 25 patients. We should, however, be cautious about expressing this as a percentage without confidence intervals that will inevitably be wide in a small study. Likewise, it is impossible to know to what extent the separation of the survival curves seen for patients with response, stable disease and progression represents a treatment effect or the natural history of their disease. Finally, including patients with stable disease in the group having 'clinical benefit' is increasingly common but difficult to interpret or justify. Nevertheless, the message of the report is that

\begin{tabular}{ll}
\hline KARGER & ( ) 2007 S. Karger GmbH, Freiburg \\
Fax +49 7614520714 & Accessible online at: \\
$\begin{array}{l}\text { E-mail Information@Karger.de } \\
\text { www.karger.com }\end{array}$ & www.karger.com/onk \\
&
\end{tabular}


this regimen is active, with response rates and time to progression (TTP) in the responders similar to those described in phase II trials.

Warm et al. [1] conclude that weekly docetaxel $35-40 \mathrm{mg} / \mathrm{m}^{2}$ is well tolerated and effective, in line with other reports [2]. So, should weekly treatment become standard? This question was explored in a preliminary manner by Tabernero et al. [3] in a randomised phase II study of 83 patients receiving docetaxel $40 \mathrm{mg} / \mathrm{m}^{2}$ for 6 weeks followed by a 2-week rest or 3-weekly docetaxel $100 \mathrm{mg} / \mathrm{m}^{2}$. A randomised phase II study is not a statistical comparison between 2 treatment arms, but an opportunity to look at the efficacy and toxicity of 2 regimens side-by-side. Tabernero et al. [3] showed that response rates, TTP and time to treatment failure, as well as grade 3 or 4 adverse events, of the two schedules were very similar but with less myelosuppression and neurosensory toxicity using the weekly regimen. More extensive comparisons of weekly and 3-weekly taxane treatment has been reported with paclitaxel in the CALGB 9840 trial in 2004 [4] and at this year's ASCO meeting in the Anglo-Celtic IV trial [5]. In this trial of over 500 patients both paclitaxel $90 \mathrm{mg} / \mathrm{m}^{2}$ weekly and $175 \mathrm{mg} / \mathrm{m}^{2}$ 3-weekly were well tolerated. Response rates were, however, significantly higher with the weekly than the 3-weekly regimen ( 43 vs. $27 \% ; p=0.002$ ). There was a trend towards longer progression-free survival with the weekly regimen, but this did not reach statistical significance ( 22 vs. 24 weeks; $p=0.06$ ). Taken with the similar results of CALGB 9840, these data support the use of weekly paclitaxel.

In conclusion, Warm et al. [1] present a valuable description of their experience with weekly docetaxel. Such reports are not phase II studies. Their value lies in helping the practising oncologist to put into standard clinical practice regimens that have been reported in formal trials conducted in highly selected populations. Weekly taxanes are certainly an alternative to 3 -weekly treatment. The choice between weekly docetaxel and weekly paclitaxel is a separate discussion.

\section{References}

1 Warm M, Nawroth F, Ohlinger R, Valter M, Pantke E, Mallmann P, Harbeck N, Kates R, Thomas A: Improvement of safety profile of docetaxel by weekly administration in patients with metastatic breast cancer. Onkologie 2007;30(8/9):DOI $10.1159 / 000104415$.

${ }_{2}$ Eniu A, Palmieri FM, Perez EA: Weekly administration of docetaxel and paclitaxel in metastatic or advanced breast cancer. The Oncologist 2005;10(9): 665-685.
Tabernero J, Climent MA, Lluch A, Albanell J, Vermorken JB, Barnadas A, Ant_n A, Laurent C, Mayordomo JI, Estaun N, Losa I, Guillem V, Garcia-Conde J, Tisaire JL, Baselga J: A multicentre, randomised phase II study of weekly or 3-weekly docetaxel in patients with metastatic breast cancer. Ann Oncol 2004;15(9):1358-1365.

4 Seidman AD, Berry D, Cirrincione C, Harris L, Dressler L, Muss H, Naughton M, Norton L, Winer E, Hudis C:CALGB 9840: Phase III study of weekly (W) paclitaxel (P) via 1-hour(h) infusion versus standard (S) $3 \mathrm{~h}$ infusion every third week in the treatment of metastatic breast cancer (MBC), with trastuzumab (T) for HER2 positive MBC and randomized for T in HER2 normal MBC. J Clin Oncol 2004;22(14S):512.

5 Verrill MW, Lee J, Cameron DA, Agrawal R, Coleman RE, McAdam K, Wardley A, Bowman A, Ferrigan L, Yellowlees A. Anglo-Celtic IV: First results of a UK National Cancer Research Network randomised phase 3 pharmacogenetic trial of weekly versus 3 weekly paclitaxel in patients with locally advanced or metastatic breast cancer (ABC). J Clin Oncol 2007;25(18S):LBA1005. 